\title{
Penerapan Pendekatan Saintifik dengan Multimedia untuk Meningkatkan Pembelajaran IPS Tema Indahnya Keragaman di Negeriku Pada Siswa Kelas IV SD Negeri 2 Karangpoh Tahun Ajaran 2019/2020
}

\author{
Heni Pratiwi, Muh. Chamdani, Tri Saptuti Susiani \\ Universitas Sebelas Maret \\ henipratiwi25_maret1998@student.uns.ac.id
}

\section{Article History}

accepted 01/06/2020

\begin{abstract}
The objectives of the research were: (1) to describe the application of scientific approach with multimedia to improve social science to the theme of Wonderful Diversity in My Country, (2) to improve social science to the theme of Wonderful Diversity in My Country, and (3) to describe constraints and solutions in applying scientific approach with multimedia. It was a collaborative classroom action research conducted in three cycles. The subjects were teachers and 29 fourth grade students. Types of data were qualitative and quantitative. Data collection techniques used test, observation, and interview. Data validation used triangulation of technique and triangulation of source. Data analysis included data reduction, data presentation, and drawing conclusions. The result showed that the percentages of social science learning outcomes were $72.4 \%$ in the first cycle, $81.03 \%$ in the second cycle, and $89.6 \%$ in the third cycle. The obstacle was the students were shy to ask questions. The solution was the teacher motivated and encouraged the students to ask questions. It concludes that the application of scientific approach with multimedia improves social science to the theme of Wonderful Diversity in My Country for fourth grade students of SD Negeri 2 Karangpoh in academic year of 2019/2020.
\end{abstract}

Keywords: scientific approach, multimedia, social science

\section{Abstrak}

Tujuan Penelitian ini yaitu: (1) mendeskripsikan penerapan pendekatan saintifik dengan multimedia dalam peningkatan pembelajaran IPS tema Indahnya Keragaman di Negeriku; (2) meningkatkan pembelajaran IPS tema Indahnya Keragaman di Negeriku; dan (3) mendeskripsikan kendala dan solusi pada penerapan pendekatan saintifik dengan multimedia. Penelitian ini merupakan penelitian tindakan kelas kolaboratif dengan tiga siklus. Subjek penelitian ini adalah guru dan siswa kelas empat. Data yang digunakan adalah data kuantitatif dan data kualitatif. Teknik pengumpulan data yang digunakan yaitu tes, observasi, wawancara. Validasi data menggunakan triangulasi teknik dan triangulasi sumber. Analisis data meliputi reduksi data, penyajian data, dan penarikan kesimpulan. Hasil penelitian ini yaitu: (1) langkah penerapan pendekatan saintifik dengan multimedia, yaitu: a. mengamati multimedia, b. menanya berdasarkan multimedia, c. mengumpulkan informasi berdasarkan multimedia, $d$. menalar dan e. mengkomunikasikan; (2) pendekatan saintifik dengan multimedia dapat meningkatkan pembelajaran IPS tema Indahnya Keragaman di Negeriku. Rata-rata ketuntasan hasil belajar IPS pada siklus I sebesar $72,4 \%$, siklus II $81,03 \%$, dan siklus III 89,6\%; (3) Kendala dalam penelitian ini yaitu siswa belum berani mengajukan pertanyaan, adapun solusi dari kendala tersebut adalah guru memotivasi dan mendorong siswa agar berani untuk mengajukan pertanyaan.

Kata kunci: pendekatan saintifik, multimedia, pembelajaran IPS. 


\section{PENDAHULUAN}

Pendidikan merupakan salah satu unsur yang sangat penting untuk meningkatkan kualitas sumber daya manusia yang mampu mengelola pembangunan nasional. Menyikapi kebutuhan pendidikan Abad 21, pemerintah melakukan penyempurnaan dalam sistem pendidikan nasional dengan memberlakukan Kurikulum 2013. Salah satu karakteristik pembelajaran di kurikulum 2013 adalah memberlakukan pembelajaran tematik di sekolah dasar untuk semua tingkatan kelas (Diputra, 2016: 126). Selama proses pembelajaran guru perlu melakukan inovasi agar pembelajaran lebih bermakna serta untuk menyesuaikan kegiatan pembelajaran dengan kurikulum yang berlaku. Berdasarkan Permendikbud Nomor 67 Tahun 2013 tentang Kerangka Dasar dan Struktur Kurikulum SD/MI, Kurikulum 2013 mulai diberlakukan pada tahun ajaran 2013/2014. Pembelajaran pada Kurikulum 2013 di jenjang sekolah dasar dilaksanakan secara tematik terpadu. Dalam pembelajaran tematik, muatan mata pelajaran diintegrasikan ke dalam tema.

Salah satu mata pelajaran yang terintegrasi ke dalam tema pada Kurikulum 2013 adalah mata pelajaran IImu Pengetahuan Sosial (IPS). IPS merupakan mata pelajaran yang sangat penting dan kompleks dalam mempelajari fenomena-fenomena sosial yang terjadi dalam masyarakat. IPS akan menjadi bekal siswa dalam kehidupan bermasyarakat (Salam, 2017: 9). Supardan (2015: 16) berpendapat, "IPS adalah istilah untuk menamai satu bidang studi atau pelajaran yang mencakup sejumlah ilmu sosial yang diorganisir untuk program-program pembelajaran di sekolah-sekolah." Sejalan dengan pendapat Surahman \& Mukminan (2017: 2) IPS adalah perpaduan antara rumpun-rumpun ilmu sosial dan humoniora untuk menciptakan perilaku sosial yang dapat memecahkan masalah sosio kebangsaan.

Berdasarkan observasi awal yang telah dilakukan peneliti pada hari Selasa tanggal 19 November 2019 kaitannya dengan pembelajaran IPS di SD Negeri 2 Karangpoh, terlihat bahwa pada saat pembelajaran berlangsung, perhatian siswa terpusat pada guru. Metode pembelajaran yang digunakan adalah metode ceramah, tanya jawab dan penugasan, serta belum menggunakan pendekatan, media dan model yang bervariasi. Media yang digunakan hanya media seadanya, seperti media gambar yang terdapat pada buku sumber. Kegiatan belajar mengajar yang berpusat pada guru mengakibatkan siswa pasif dalam pembelajaran. Ketidaktertarikan siswa tersebut ditunjukkan oleh perilaku siswa yang kurang paham dengan materi yang diajarkan.

Selain observasi, peneliti juga melakukan wawancara kepada guru kelas. Menurut guru kelas IV SD Negeri 2 Karangpoh, metode pembelajaran yang sering digunakan adalah metode ceramah, tanya jawab dan penugasan. Dalam kegiatan pembelajaran guru sudah berusaha mengajak siswa untuk aktif bertanya ketika ada kesulitan, namun sebagian siswa kurang tertarik terhadap pembelajaran IPS. Materi IPS tergolong materi yang sulit karena muatan materi dalam pembelajaran IPS didominasi dengan hafalan, sehingga siswa mengandalkan hafalan daripada pemahaman materi.

Berdasarkan data hasil Penilaian Tengah Semester (PTS) menunjukkan bahwa tingkat pemahaman siswa terhadap muatan IPS masih rendah yakni belum mencapai Kriteria Ketuntasan Minimal (KKM). Masih banyak nilai siswa yang belum mencapai KKM yang sudah di tetapkan yaitu 75. Hasil Penilaian Tengah Semester (PTS) semester ganjil di kelas IV SD Negeri 2 Karangpoh tahun ajaran 2019/2020 menunjukkan bahwa hasil PTS muatan IPS dari jumlah 29 siswa hanya 13 siswa atau sebesar $44,83 \%$ saja yang mendapat nilai di atas KKM, sedangkan yang mendapat nilai di bawah KKM sebanyak 16 siswa atau sebesar 55,17\%.

Dari uraian di atas, alternatif pemecahan masalah yang sesuai untuk mengatasi permasalahan tersebut adalah dengan menggunakan pendekatan saintifik dengan multimedia. Pendekatan saintifik merupakan salah satu pendekatan yang inovatif yang mencakup tiga ranah sekaligus, yaitu sikap, pengetahuan, dan keterampilan (Shoimin, 
2016: 165). Menurut Bermawi dan Fauziah (2016: 65) penggunaan pendekatan saintifik dapat membuat siswa lebih aktif karena siswa mencari tahu informasi dari berbagai sumber. Pendapat tersebut didukung oleh Gerde, Schachter, dan Wasik (2013: 315) yang menjelaskan bahwa penggunaan metode ilmiah untuk mengeksplorasi ilmu pengetahuan kepada anak-anak dengan memberikan cara yang sistematis agar menarik atau melibatkan anak dalam kegiatan mengamati, menanya, memprediksi, mencoba, meringkas, dan menyampaikan hasil. Tujuan pendekatan saintifik yaitu mengajak siswa untuk terlibat aktif dalam pembelajaran untuk mencari tahu dari berbagai sumber dimanapun dan kapanpun, sehingga tidak hanya mendapat informasi dari guru yang sifatnya searah (Noviyanti, 2017: 47). Langkah-langkah pendekatan saintifik menurut Dyer (Sani, 2015: 53), yaitu: (a) mengamati; (b) menanya; (c) mencoba/mengumpulkan informasi; (d) menalar/asosiasi; (e) membentuk jejaring/melakukan komunikasi.

Untuk mendapatkan hasil yang lebih optimal pendekatan saintifik dapat dikombinasikan dengan multimedia. Menurut Ziden \& Rahman (2013: 212) menyatakan bahwa "multimedia is a combination of two of more elements wicht include text, graphics, audio, video or animation". Hal tersebut sejalan dengan pendapat Arsyad (2015: 162) mengemukakan bahwa, "multimedia merupakan kombinasi antara teks, grafik, animasi, suara, dan video".

Penelitian ini bertujuan untuk: (1) Mendeskripsikan penerapan pendekatan saintifik dengan multimedia dalam peningkatan pembelajaran IPS tema Indahnya Keragaman di Negeriku pada siswa kelas IV SD Negeri 2 Karangpoh tahun ajaran 2019/2020, (2) Meningkatkan pembelajaran IPS tema Indahnya Keragaman di Negeriku pada siswa kelas IV SD Negeri 2 Karangpoh tahun ajaran 2019/2020, (3) Mendeskripsikan kendala dan solusi penerapan pendekatan saintifik dengan multimedia dalam peningkatan pembelajaran IPS tema Indahnya Keragaman di Negeriku pada siswa kelas IV SD Negeri 2 Karangpoh tahun ajaran 2019/2020.

\section{METODE}

Penelitian ini adalah jenis Penelitian Tindakan Kelas (PTK) Kolaboratif. Menurut Suyanto (Muslich, 2013: 9) PTK merupakan suatu bentuk penelitian yang bersifat reflektif dengan melakukan tindakan-tindakan tertentu agar dapat memperbaiki dan/atau meningkatkan praktik-praktik pembelajaran dikelas secara profesional. Subjek pada penelitian tindakan kelas ini adalah guru dan siswa kelas IV SD Negeri 2 Karangpoh tahun ajaran 2019/2020. Data yang digunakan adalah data kuantitatif yaitu berupa hasil observasi guru, hasil observasi siswa, hasil penilaian proses siswa, dan hasil belajar siswa pada muatan IPS tema Indahnya Keragaman di Negeriku. Sedangkan data kualitatif berupa hasil wawancara terhadap guru dan siswa melalui penerapan pendekatan saintifik dengan multimedia dalam peningkatan pembelajaran IPS. Teknik pengumpulan data mengunakan teknik tes dan non tes. Validitas data menggunakan triangulasi sumber dan teknik. Analisis data meliputi reduksi data, penyajian data, dan penarikan kesimpulan (Sugiyono, 2017: 244). Indikator kinerja penelitian ini adalah penerapan pendekatan saintifik dengan multimedia dalam pembelajaran melalui observasi dan wawancara sebesar $85 \%$ dan peningkatan hasil belajar IPS tema Indahnya Keragaman di Negeriku dengan jumlah siswa tuntas di atas $85 \%$ dengan KKM 76. Adapun prosedur penelitian yang digunakan adalah modifikasi dari Arikunto (2013: 137) yang pada masing-masing siklusnya terdiri dari empat tahap yaitu perencanaan, pelaksanaan, pengamatan, dan refleksi.

\section{HASIL DAN PEMBAHASAN}

Penelitian ini dilaksanakan selama tiga siklus dengan menerapkan lima langkah pendekatan saintifik yang meliputi: (1) mengamati multimedia; (2) menanya berdasarkan multimedia; (3) mengumpulkan informasi berdasarkan multimedia; (4) 
menalar; dan (5) mengkomunikasikan. Langkah-langakah tersebut mengacu dari pendapat yang dikemukakan oleh Hosnan (2014: 82), Dyer (Sani, 2017: 53) dan lampiran Kemendikbud dalam peraturannya Nomor 81A Tahun 2013 tentang implementasi kurikulum.

Tabel 1. Perbandingan Hasil Observasi Penerapan Pendekatan Saintifik dengan Multimedia terhadap Guru Tiap Siklus

\begin{tabular}{|c|c|c|c|}
\hline Langkah-langkah & Siklus I & Siklus II & Siklus III \\
\hline Mengamati Multimedia & 85,42 & 89,58 & 94,79 \\
\hline Menanya Berdasarkan Multimedia & 75 & 84,72 & 93,06 \\
\hline $\begin{array}{l}\text { Mengumpulkan } \\
\text { Berdasarkan Multimedia }\end{array}$ & 83,33 & 87,5 & 90,63 \\
\hline Menalar & 78,13 & 82,29 & 87,5 \\
\hline Mengkomunikasikan & 71,67 & 77,5 & 85,83 \\
\hline Rata-rata & 78,71 & 84,32 & 90,36 \\
\hline
\end{tabular}

Berdasarkan tabel 1, diketahui bahwa hasil observasi penerapan pendekatan saintifik dengan multimedia terhadap guru pada siklus I persentase rata-rata mencapai 78,71. Skor ini belum memenuhi indikator kinerja penelitian, sehingga penelitian dilanjutkan ke siklus II dengan harapan pembelajaran lebih baik. Hasil pelaksanaan siklus II terdapat peningkatan dari siklus I yaitu mencapai $84,32 \%$. Skor ini belum memenuhi indikator kinerja peneltian, sehingga penelitian dilanjutkan ke siklus III. Pembelajaran siklus III dilaksanakan berdasarkan refleksi siklus II agar hasil pembelajaran pada siklus III menjadi lebih baik. Hasil pelaksanaan siklus III terdapat peningkatan dari siklus II yaitu mencapai $90,36 \%$.

Tabel 2. Perbandingan Hasil Observasi Penerapan Pendekatan Saintifik dengan Multimedia terhadap Siswa Tiap Siklus

\begin{tabular}{|c|c|c|c|}
\hline Langkah-langkah & Siklus I & Siklus II & Siklus III \\
\hline Mengamati Multimedia & 83,33 & 87,5 & 93,75 \\
\hline Menanya Berdasarkan Multimedia & 72,22 & 84,72 & 92,36 \\
\hline $\begin{array}{l}\text { Mengumpulkan } \\
\text { Berdasarkan Multimedia }\end{array}$ & 79,17 & 85,42 & 90,63 \\
\hline Menalar & 75 & 79,17 & 87,5 \\
\hline Mengkomunikasikan & 67,5 & 77,5 & 85 \\
\hline Rata-rata & 75,44 & 82,86 & 89,85 \\
\hline
\end{tabular}

Berdasarkan tabel 2, diketahui bahwa hasil observasi penerapan pendekatan saintifik dengan multimedia terhadap siswa pada siklus I persentase rata-rata mencapai $75,44 \%$. Hasil pelaksanaan siklus II terdapat peningkatan dari siklus I yaitu mencapai $82,86 \%$. Hasil pelaksanaan siklus III terdapat peningkatan dari siklus II yaitu mencapai 89,85\%.

Sehubungan dengan peningkatan pembelajaran IPS tema Indahnya Keragaman di Negeriku, peneliti melakukan analisis hasil penilaian proses dan hasil belajar yang dilakukan setiap pertemuan pada siklus I, II dan III. Pada siklus I didapatkan hasil penilaian proses mencapai $77,5 \%$ siswa yang tuntas dengan rata-rata nilai 79 . Pada siklus II didapatkan hasil penilaian proses mencapai $84,4 \%$ siswa yang tuntas dengan 
rata-rata nilai 82,5. Kemudian, pada siklus III didapatkan hasil penilaian proses mencapai 91,4\% siswa yang tuntas dengan rata-rata nilai 86,45.

Analisis hasil penilaian juga dilakukan pada penilaian hasil belajar setiap pertemuan di siklus I, II dan III. Pada siklus I didapatkan penilaian hasil belajar mencapai $72,4 \%$ siswa yang tuntas dengan rata-rata nilai 82,5 . Pada siklus II didapatkan penilaian hasil belajar $81,03 \%$ siswa yang tuntas dengan rata-rata nilai 84,2 . Kemudian, pada siklus III didapatkan penilaian hasil belajar $89,6 \%$ dengan ratarata nilai 87,3 . Sehingga, dapat disimpulkan bahwa penilaian proses dan hasil belajar IPS tema Indahnya Keragaman di Negeriku selalu meningkat tiap siklusnya.

Berdasarkan hasil dan pembahasan yang telah diuraikan dapat diketahui bahwa hasil observasi dan wawancara penerapan pendekatan saintifik dengan multimedia setiap siklusnya selalu meningkat dan telah mencapai indikator kinerja penelitian begitu pun dengan hasil penilaian proses dan belajar IPS siswa pada setiap siklus yang selalu mengalami peningkatan dan telah mencapai indikator kinerja penelitian. Sejalan dengan penelitian yang dilakukan Fahmi, M.N (2017: 116) bahwa pendekatan saintifik dapat meningkatkan aktivitas siswa sehingga berpengaruh pada peningkatan hasil. Hal ini diperkuat oleh penelitian yang dilakukan oleh Dewi dan Mukminan (2016: 30-31) yang menunjukkan proses implementasi pendekatan saintifik pada pembelajaran IPS di middle grade SD Tumbuh 3 Kota Yogyakarta telah berjalan dengan cukup baik karena pelaksanaan pendekatan saintifik sudah membudaya dan tidak mengalami kendala cukup berarti, kesesuaian antara pendekatan saintifik dengan karakteristik anak middle grade telah terbukti melalui pembelajaran IPS yang menyenangkan. Kemudian, mengenai peningkatan persentase penilaian proses dari siklus I sampai III sejalan dengan pendapat Zhong (2014: 1507-1508) yang berpendapat pendekatan saintifik tidak hanya dapat merangsang perhatian siswa dan memperbaiki pengaruh pengajaran, tetapi juga melatih kemampuan belajar mandiri dan kemampuan inovatif siswa.

Kendala pendekatan saintifik dengan multimedia untuk meningkatkan pembelajaran IPS Tema Indahnya Keragaman di Negeriku pada siswa kelas IV SD Negeri 2 Karangpoh tahun ajaran 2019/2020 yaitu: (1) siswa belum berani mengajukan pertanyaan yang belum dipahami; (2) siswa belum berani menyampaikan pendapat; dan (3) siswa tidak menuliskan hasil diskusi pada buku. Solusinya yaitu: (1) guru memberikan stimulus agar siswa aktif bertanya; (2) guru memancing siswa agar berani menyampaikan pendapat; dan (3) guru mengarahkan siswa agar menuliskan hasil diskusi pada buku.

\section{SIMPULAN}

Berdasarkan uraian di atas, dapat disimpulkan: (1) Penerapan pendekatan saintifik dengan multimedia dalam peningkatan pembelajaran IPS Tema Indahnya Keragaman di Negeriku pada siswa kelas IV SD Negeri 2 Karangpoh tahun ajaran 2019/2020 dilaksanakan melalui lima langkah yaitu: (a) mengamati multimedia; (b) menanya berdasarkan multimedia; (c) mengumpulkan informasi berdasarkan multimedia; (d) menalar; (e) mengkomunikasikan; (2) Penerapan pendekatan saintifik dapat meningkatkan pembelajaran IPS tema Indahnya Keragaman di Negeriku. Hal ini ditunjukkan dengan rata-rata ketuntasan hasil belajar IPS pada siklus I sebesar $72,4 \%$, siklus II 81,03\%, dan siklus III 89,6\%; (3) Kendala dalam penelitian ini adalah siswa belum berani mengajukan pertanyaan, adapun solusi dari kendala tersebut adalah guru memotivasi dan mendorong siswa agar berani untuk mengajukan pertanyaan.

Peneliti mengajukan saran sebagai berikut: (1) guru sebaiknya lebih memperhatikan langkah-langkah penerapan pendekatan saintifik dengan multimedia agar pelaksanaan pembelajaran lebih baik tidak ada kendala yang muncul; (2) siswa sebaiknya lebih berani dalam menyampaikan pendapat ketika berdiskusi maupun kegiatan presentasi; (3) pihak sekolah sebaiknya menyediakan sarana pembelajaran 
yang lengkap, salah satunya adalah menyediakan media pembelajaran yang memadai sehingga guru dapat meningkatkan kreativitas saat mengajar; dan (4) pembaca/peneliti lain hendaknya hasil penelitian ini bisa menjadi referensi untuk lebih mempersiapkan dan menguasai materi sebelum melakukan penelitian.

\section{DAFTAR PUSTAKA}

Arikunto, S. (2013). Prosedur Penelitian Suatu Pendekatan Praktik. Jakarta: Rineka Cipta.

Arsyad, A. (2015). Media Pembelajaran. Jakarta: PT Raja Grafindo Persada.

Bermawi, Y \& Fauziah, T. (2016). Penerapan Pendekatan Saintifik dalam Pembelajaran di Sekolah Dasar Aceh Besar. Jurnal Pesona Dasar, 2 (4), 6371. Diperoleh pada tanggal 22 November 2019 dari http:// www. jurnal. unsiyah.ac.id/.

Dewi, A. E. A. \& Mukminan. (2016). Implementasi Pendekatan Saintifik dalam Pembelajaran IPS di Midle Grade SD Tumbuh 3 Kota Yogyakarta. Jurnal Prima Edukasi, 4 (1). 20-31. Diperoleh pada tanggal 22 November 2019 dari https://journal.uny.ac.id/.

Diputra, K. (2016). Pengembangan Multimedia Pembelajaran Tematik Integratif Untuk Siswa Kelas IV Sekolah Dasar. Jurnal Pendidikan Indonesia, 5 (2). Diperoleh pada tanggal 25 November 2019 dari https://ejournal.undiksha.ac.id.

Fahmi, M., N. (2017). Penerapan Pendekatan Saintifik untuk Meningkatkan Aktivitas dan Hasil Belajar Siswa pada Mata Pelajaran IPS Kelas IV SDN Tambakromo 2 Ngawi. Jurnal Pendidikan Dasar Nusantara. Vol. 3 No. 1. Diunduh pada tanggal 25 November 2019 dari http://ojs.unpkediri.ac.id.

Gerde, H.K., Schachter, R.E., \& Wasik, B.A. (2013). Using The Scientific Methode to Guide Learning: An Integrated Approach to Early Childhood Curriculum. Early Chilhood Education Journal, 41 (5), 315-323.

Hosnan. (2014). Pendekatan Saintifik dan Kontekstual dalam Pembelajaran Abad 21. Bogor: Ghalia Indonesia.

Kemendikbud. (2013). Peraturan Menteri Pendidikan dan Kebudayaan Republik Indonesia Nomor 81A Tahun 2013 tentang Implementasi Kurikulum. Jakarta: Kementerian Pendidikan dan Kebudayaan.

Muslich, M. (2013). Melaksanakan Penelitian Tindakan Kelas Itu Mudah. Jakarta: Bumi Aksara.

Noviyanti, E. (2017). Pendekatan Saintifik dan Kontekstual dalam Pembelajaran Literasi Sains di Sekolah Dasar. Prosiding Seminar Nasional. Diperoleh pada tanggal $10 \quad$ Desember $2019 \quad$ dari https://eprints.umk.ac.id/7379/9/6_Erna_Unissula.pdf.

Permendikbud Nomor 67 Tahun 2013, tentang Kerangka Dasar dan Struktur Kurikulum Sekolah/Madrasah Ibtidaiyah.

Salam, R. (2017). Model Pembelajaran Inkuiri Sosial dalam Pembelajaran IPS. Jurnal Harmony. Vol 2 (1). Hal 7- hal 12. Diperoleh pada tanggal 25 November 2019 dari https://journal.unnes.ac.id/.

Sani, R.A. (2017). Pembelajaran Saintifik Untuk Implementasi Kurikulum 2013. Jakarta: Bumi Aksara.

Shoimin, A. (2016). 68 Model Pembelajaran Inovatif Dalam Kurikulum 2013. Yogyakarta: Ar-Ruzz Media.

Supardan, D. (2015). Pembelajaran Ilmu Pengetahuan Sosial. Jakarta: Bumi Aksara.

Sugiyono. (2017). Statistika Untuk Penelitian. Bandung: Alfabeta.

Surahman, E \& Mukminan. (2017). Peran Guru sebagai Pendidik dan Pengajar dalam Meningkatkan Sikap Sosial dan Tanggung Jawab Sosial Siswa SMP. Harmoni Sosial: Jurnal Pendidikan IPS. Vol. 4. No. 1. Diperoleh pada tanggal 25 November 2019 dari http://journal.uny.ac.id/index.php/hsjpi. 
Volume 8 Nomor 2 Tahun 2020

Ziden, Abu., A \& Rahman, Abdul., F., M. (2013). The effectiveness of Web-Based Multimedia Application Simulation in Teaching and Learning. International Journal of Instructions. Vol. 6 No. 6. Diperoleh pada tanggal 25 November 2019 dari http://www.e-iji.net. 